\title{
Reuven Amitai \& Michal Biran (eds.). Nomads as Agents of Cultural Change. The Mongols and Their Eurasian Predecessors
}

\section{Denise Aigle}

\section{(2) OpenEdition \\ 1 Journals}

Édition électronique

URL : http://journals.openedition.org/abstractairanica/46497

DOI : 10.4000/abstractairanica.46497

ISBN : 1961-960X

ISSN : 1961-960X

Éditeur :

CNRS (UMR 7528 Mondes iraniens et indiens), Éditions de l'IFRI

\section{Référence électronique}

Denise Aigle, « Reuven Amitai \& Michal Biran (eds.). Nomads as Agents of Cultural Change. The Mongols and Their Eurasian Predecessors ", Abstracta Iranica [En ligne], Volume 37-38-39 | 2018, document 7, mis en ligne le 30 décembre 2018, consulté le 26 septembre 2020. URL : http://journals.openedition.org/ abstractairanica/46497 ; DOI : https://doi.org/10.4000/abstractairanica.46497

Ce document a été généré automatiquement le 26 septembre 2020.

Tous droits réservés 


\title{
Reuven Amitai \& Michal Biran (eds.). Nomads as Agents of Cultural Change. The Mongols and Their Eurasian Predecessors
}

\author{
Denise Aigle
}

\section{RÉFÉRENCE}

Reuven Amitai \& Michal Biran (eds.). Nomads as Agents of Cultural Change. The Mongols and Their Eurasian Predecessors. Honolulu: University of Hawaii Press, 2015, 345 p., ISBN: 9780824839789

1 Cet ouvrage est issu d'une conférence organisée à l'Université Hébraïque de Jérusalem qui s'était tenue en 2006 sur le rôle des nomades comme "agents des échanges culturels » dans l'Eurasie pré-moderne. Après l'introduction de Michal Biran, les douze contributions ici rassemblées peuvent être regroupées en trois ensembles. Les quatre premiers chapitres examinent ce phénomène en Asie orientale et occidentale dans l'Antiquité et pendant le Haut Moyen Âge (Gideon Shelech-Lavi, Anatoly Khazanov, William Honeychurch et İsenbike Togan), le cœur de l'ouvrage est consacrée à l'Empire mongol aux XIII et XIV ${ }^{\mathrm{e}}$ siècles (Thomas Allsen, Michal Biran, George Lane et Morris Rossabi, voir les recensions séparées sur ces articles), enfin les trois derniers chapitres (Reuven Amitai, István Vásáry et David Morgan) s'intéressent à différents aspects de l'héritage mongol.

On a longtemps considéré que les nomades de l'Eurasie centrale se seraient appropriés le savoir de leurs voisins sédentaires et vice et versa. Cependant, comme le note Michal Biran dans son introduction: "Such appropriation is often described as 'barbarian' assimilation into more elaborated sedentary culture or as proof of the nonautarkic character of nomadic culture » (p. 5). Elle explique que la situation est plus complexe : 
«Instead, this amalgamation could better be described part of the Inner Asia mode of gouvernance and is consistent with multicultural outlook of Inner Asia nomads » (p. 5). Les recherches menées depuis de nombreuses années montrent en effet que les nomades étaient non seulement des conquérants militaires, mais aussi des agents de l'échange culturel. Les travaux de Thomas Allsen ont mis en évidence le rôle des Mongols dans les échanges entre l'Asie de l'Est et de l'Ouest dans des domaines tels que la technologie, l'agriculture, l'historiographie et la cartographie (Thomas T. Allsen, "Closer Encounters: The Appropriation of Culture and the Apportionment of Peoples in the Mongol Empire ", Journal of Early Modern History, vol. 1/1, 1997, p. 2-23 ; Id., Culture and Conquest in Mongol Eurasia, Cambridge, 2001). Dans Nomads as Agents of Cultural Change, les auteurs cherchent à appliquer la thèse d'Allsen à de nouveaux contextes.

3 Les éditeurs ont très utilement regroupé toutes les études et sources utilisées par les auteurs (p. 283-329) et composé un index (p. 335-345). On peut néanmoins regretter qu'il n'y ait pas de conclusion générale qui ferait la synthèse entre les différents chapitres de l'ouvrage. Par ailleurs, aucune carte ne permet aux lecteurs de localiser des lieux peu connus, dont beaucoup n'existent plus. L'ouvrage ne comporte en effet que deux cartes très générales (l'Eurasie, p. $x$ et les quatre khanats mongols en 1290, p. 118). Néanmoins, on ne peut que féliciter Reuven Amitai et Michal Biran pour avoir produit un volume qui souligne à nouveau l'importance historique des Mongols et permet de mieux comprendre le rôle de la steppe dans l'histoire mondiale.

\section{AUTEURS}

DENISE AIGLE

UMR 8167 - Orient et Méditerranée 